Personalidade Acadêmica Homenageada:

Raymundo Juliano Feitosa (Universidade Federal do Rio Grande do Norte - UFRN)

\title{
OS BECOS TÊM OUVIDOS: A LUTA PELA PROTEÇÃO AOS DEFENSORES DE DIREITOS HUMANOS EM MINAS GERAIS
}

\section{VITÓRIA GABRIELE CHAVES ROSA}

Graduanda em Direito, modalidade integral, pela Escola Superior Dom Helder Câmara. Belo Horizonte - MG. E-mail: vitoriagchavesrosa@gmail.com

\section{CAIO AUGUSTO SOUZA LARA}

Mestre e Doutor em Direito pela Faculdade de Direito da Universidade Federal de Minas Gerais - UFMG. Professor da Escola Superior Dom Helder Câmara. Pesquisador Associado ao Programa RECAJ-UFMG - Acesso à Justiça e Solução de Conflitos. Secretário de Comunicação do Conselho Nacional de Pesquisa e Pósgraduação em Direito - CONPEDI. Belo Horizonte-MG. Email:caiolarabh@yahoo.com.br.

\section{RESUMO}

O tema-problema da pesquisa que se pretende desenvolver é a efetividade dos programas de proteção aos defensores de Direitos Humanos em Minas Gerais. Em 2017, o Brasil se apresentou como o país onde mais se mata defensores de Direitos Humanos nas Américas, segundo relatórios das organizaçōes internacionais Anistia Internacional e Global Witness. $O$ assassinato político da vereadora e ativista Marielle Franco, no estado do Rio de Janeiro, em março de 2018, que ganhou atenção da mídia nacional e internacional, retrata a perduração do problema até os dias atuais, visto que não apenas Marielle, como centenas de ativistas pelo Brasil, são ameaçados e assassinados em consequência de suas lutas. Tal fato retrata a vulnerabilidade das minorias no cenário brasileiro, que urge em ser combatida. A ONU, em sua Declaração dos Defensores de Direitos Humanos 
Personalidade Acadêmica Homenageada:

Raymundo Juliano Feitosa (Universidade Federal do Rio Grande do Norte - UFRN)

(1998), destaca a importância de cada Estado na criação de medidas de proteção a esses ativistas em situações vulneráveis. No Brasil, foi decretado em 2004 a implantação do Programa de Proteção aos Defensores de Direitos Humanos (PPDDH), o qual possui convênios nos estados de Minas Gerais, Pernambuco, Maranhão e Ceará. Em Minas Gerais, o programa foi adotado em 2009, e foi instituído oficialmente em 2014, pela Lei Estadual 21.164/2014. O PPDDH-MG atende cerca de 69 defensores em 32 municípios mineiros e a capital, Belo Horizonte. No estado, os quilombolas e defensores da terra são a maioria programa, uma vez que são indicados como os mais ameaçados e afetados por tais estatísticas. O problema objeto da investigação científica proposta é: quais são os maiores desafios enfrentados pelo Programa de Proteção aos Defensores de Direitos Humanos em Minas Gerais? A partir das reflexões preliminares sobre o tema, afirma-se que os programas são de extrema importância para os defensores de Direitos Humanos. Supõe-se, porém, que estes programas possuam sua efetividade em risco diante a um cenário em que comentários de ódio se tornam frequentes na comunidade política e sociedade brasileira em geral. Teme-se também que o corte de gastos atinja a esses programas, de modo a interferir negativamente na efetividade do Programa de Proteção aos Defensores de Direitos Humanos em Minas Gerais, visto a necessidade de recursos financeiros e apoio estatal para o custeio das equipes, transporte, entre outros. $O$ objetivo geral do trabalho é analisar qual o impacto efetivo do Estado na proteção daqueles que lutam para defender os Direitos Humanos diariamente, e que muitas vezes, em consequência de seu ativismo, encontram-se em situação de vulnerabilidade, alvos de violência e perseguição. A pesquisa que se propõe pertence à vertente metodológica jurídico-sociológica. No tocante ao tipo de investigação, foi escolhido, na classificação de Witker (1985) e Gustin (2010), o tipo jurídico-projetivo. O raciocínio desenvolvido na pesquisa será predominantemente dialético. De acordo com a técnica de análise de conteúdo, afirma-se que se trata de uma pesquisa teórica, o que é possível a partir da análise de conteúdo dos textos doutrinários, normas e demais dados colhidos na pesquisa. Como conclusão parcial do trabalho, têm-se que o PPDDH-MG possui capacidade de ação limitada, uma vez que 
Personalidade Acadêmica Homenageada:

Raymundo Juliano Feitosa (Universidade Federal do Rio Grande do Norte - UFRN)

restrições orçamentárias não são os únicos possíveis empecilhos encontrados pelo programa. Existe, de maneira mais expressiva, a falta de articulação com políticas públicas, que mantém a vulnerabilidade dos defensores. Além disso, para a maioria dos casos não há investigação cuidadosa dos casos, o que acarreta em uma grande taxa de impunidade.

PALAVRAS-CHAVE: Direitos Humanos; Defensores; Proteção; Efetividade; Estados.

\section{REFERÊNCIAS}

ANISTIA INTERNACIONAL. Informe 17/18: O Estado dos Direitos Humanos no Mundo. Disponível em https://anistia.org.br/wpcontent/uploads/2018/02/informe2017-18-online1.pdf. Acesso em 04 abr. 2019.

CARVALHO, Sandra; SOUZA, Alice de Marchi Pereira de; DIAS, Rafael Medonça. Protection policies for Human Rights defenders. SUR 23, São Paulo, v.3 n.23, p. 175-184, 2016. Disponível em https://sur.conectas.org/wpcontent/uploads/2016/09/14-sur-23-portugues-sandra-alice-e-rafael.pdf. Acesso em 22 abr. 2019.

GRANDELLE, Renato. Baixo efetivo e desinteresse dos estados deixam sem proteção ativistas ameaçados. O GLOBO. Disponível em https://oglobo.globo.com/sociedade/baixo-efetivo-desinteresse-de-estados-deixamsem-protecao-ativistas-ameacados-22837962. Acesso em 01 maio 2019.

GUSTIN, Miracy Barbosa de Sousa; DIAS, Maria Tereza Fonseca. (Re)pensando a pesquisa jurídica: teoria e prática. 3ª . ed. Belo Horizonte: Del Rey, 2010.

INSTITUTO DH. Programa de Proteção aos Defensores de Direitos Humanos. Disponível em https://institutodh.org/ppddh/. Acesso em 22 abr. 2019.

LELIS, Henrique Rodrigues; LÔBO, Edilene. A dimensão cultural dos Direitos Humanos e a efetivação democrático de Direito. Revista Jurídica UNICURITIBA, Curitiba, v. 3, p. 734-758, 2016. Disponível em http://revista.unicuritiba.edu.br/index.php/RevJur/article/view/1894/1262. Acesso em 20 maio 2019.

ORGANIZAÇÃO DAS NAÇÕES UNIDAS. Declaration on the Right and Responsibility of Individuals, Groups and Organs of Society to Promote and Protect Universally Recognized Human Rights and Fundamental Freedoms. 
Personalidade Acadêmica Homenageada:

Raymundo Juliano Feitosa (Universidade Federal do Rio Grande do Norte - UFRN)

1998.

Disponível

em

https://www.ohchr.org/Documents/lssues/Defenders/Declaration/declaration.pdf. Acesso em 22 abr. 2019.

Human Rights Defenders: Protecting the Right to Defend Human Rights. Disponível em https://www.ohchr.org/Documents/Publications/FactSheet29en.pdf. Acesso em 22 abr. 2019.

PINTO, João Batista Moreira Pinto (Org.). Os Direitos Humanos como projeto de sociedade: caracterização e desafios. Belo Horizonte: Instituto DH, 2018. .v. 1. 376p.

SMANIOTTO, Melissa Andréa. Direitos humanos e diversidade. Ponta Grossa (PR): Atena Editora, 2019. v. 2.

WITKER, Jorge. Como elaborar uma tesis en derecho: pautas metodológicas y técnicas para el estudiante o investigador del derecho. Madrid: Civitas, 1985. 